\title{
Increasing use of artemisinin-based combination therapy for treatment of malaria infection in Nigerian hospitals
}

\author{
Nneka U. IGBOELI, Chinwe V. UKWE, Obinna I. EKWUNIFE.
} Received (first version): 16-Jul-2010 Accepted: 28-Nov-2010

\begin{abstract}
${ }^{*}$
Objectives: This study aimed at describing the pattern of outpatient antimalarial drug prescribing in a secondary and a tertiary hospital, and to assess adherence to the National Antimalarial Treatment Guideline (ATG)

Methods: An audit of antimalarial prescription files from the two health facilities for a period of six months in 2008 was conducted. Semi structured questionnaires were used to collect information from the doctors and pharmacists on their awareness and knowledge of the National Antimalarial Treatment Guideline.

Results: Artemisinin-based combination therapies (ACTs) were the most prescribed antimalarials. Overall, $81.4 \%$ of the total prescriptions contained ACTs, out of which $56.8 \%$ were artemetherlumefantrine. However, adherence to the drugs indicated by national guideline within the DU90\% was $38.5 \%$ for the tertiary and $66.7 \%$ for the secondary hospital. The standard practice of prescribing with generic name was still not adhered to as evidenced in the understudied hospitals. The percentage of health care providers that were aware of the ATG was $88.2 \%$ for doctors and $85.1 \%$ for pharmacists. However, $13.3 \%$ and $52.2 \%$ of doctors and pharmacists respectively could not properly list the drugs specified in the guideline. Amodiaquine was the most commonly preferred option for managing children aged $0-3$ months with malaria infection against the indicated oral quinine. Conclusion: This study showed an increased use of artemisinin-based combination therapy for the treatment of uncomplicated malaria compared previous reports in Nigeria. This study also highlights the need for periodic in-service quality assurance among health professionals with monitoring of adherence to and assessment of knowledge of clinical guidelines to ensure the practice of evidence based medicine.
\end{abstract}

Keywords: Guideline Adherence. Antimalarials. Nigeria.

\footnotetext{
*Nneka U. IGBOELI. M.Pharm. Department of Clinical Pharmacy and Pharmacy Management. Faculty of Pharmaceutical Sciences, University of Nigeria. Nsukka (Nigeria).

Chinwe V. UKWE. PhD. Department of Clinical Pharmacy and Pharmacy Management. Faculty of Pharmaceutical Sciences, University of Nigeria. Nsukka (Nigeria). Obinna I. EKWUNIFE. M.Pharm. Department of Clinical Pharmacy and Pharmacy Management. Faculty of Pharmaceutical Sciences, University of Nigeria. Nsukka (Nigeria).
}

\author{
AUMENTO DEL USO DE TRATAMIENTOS \\ COMBINADOS CON ARTEMISINA PARA \\ EL TRATAMIENTO DE LA INFECCIÓN DE \\ MALARIA EN HOSPITALES NIGERIANOS
}

\section{RESUMEN}

Objetivos: Este estudio trató de describir el patrón de prescripción ambulatoria de antimaláricos en un hospital secundario y terciario, y evaluar el cumplimiento de la Guía Nacional de Tratamiento Antimalárico (ATG).

Métodos: Se realizó un audit de los archivos de prescripción de antamaláricos en dos establecimientos sanitarios de un periodo de seis meses en 2008. Se utilizaron cuestionarios semiestructurados para recoger informaciones del conocimiento de médicos y farmacéuticos de la Guía Nacional de Tratamiento Antimalárico. Resultados: Los tratamientos de combinación con artemisina (TCA) fueron los antimaláricos más prescritos. Del total de prescripciones, el $81,4 \%$ TCA, de las cuales el 56,8\% eran artemeterlumefantrina. Sin embargo, el cumplimiento de los medicamentos indicados en las guías nacionales con el DU90\% fue del $38,5 \%$ en el hospital terciario y del 66,7\% en el secundario. La práctica de prescripción por nombre genérico todavía no era seguida en ninguno de los hospitales. El porcentaje de profesionales sanitarios que conocía las TCA era del $88,2 \%$ de los médicos y del $85,1 \%$ de los farmacéuticos. Sin embargo, el 13,3\% y el 52,2\% de médicos y farmacéuticos, respectivamente, no pudo enunciar adecuadamente la lista de medicamentos especificados en la guía. La amodiaquina fue la opción más frecuentemente preferida para tratar a niños de 0-3 meses con infección de malaria, en lugar de la indicada quinina oral.

Conclusión: Este estudio mostró un aumento del uso de regímenes de combinación con artemisina para tratamiento de malaria no complicada en comparación con anteriores informes de Nigeria. Este estudio también remarca la necesidad de un periódico aseguramiento de la calidad interno entre los profesionales sanitarios, monitorizando el cumplimiento y el conocimiento de las guías clínicas para asegurar la práctica basada en la evidencia.

Palabras clave: Cumplimiento de guías. Antimaláricos. Nigeria. 


\section{INTRODUCTION}

Malaria is a major public health problem in Nigeria. It remains one of the five leading causes of outpatient visits and mortality especially in children under five years of age. ${ }^{1}$ One of the major strategies to control malaria is prompt management with effective antimalarial drugs. Unfortunately, this has received a major setback in the past years because of the high level of resistance to affordable antimalarial drugs such as chloroquine and sulphadoxine-pyrimethamine. Both the broad collapse of preventive efforts and the waning efficacy of standard antimalarial drugs ${ }^{2,3}$, account for the global resurgence of malaria. New therapies are available, but the use of older drugs persists for social, economic and clinical reasons despite resistance of the organisms to the older drugs. ${ }^{4}$ Following World Health Organization (WHO) recommendations, more than 60 countries have now adopted Artemisinin-based combination therapies (ACTs), of which Nigeria is one of them. However, inappropriate use or poor adherence may lead to failure of these new combination therapies.

Drug utilization studies are carried out to identify associated problems with drug use since adherence of health providers and patients to recommendations of a treatment policy is key to the overall success of such guidelines. Drug utilization studies could identify associated problems with drug use and provide feedback to the prescriber so as to create awareness for rational use of drugs. ${ }^{5}$ As such, antimalarial utilization studies are important in effort to redress the impact of malaria as it will ensure that care providers are working in concert with National strategy.

In Nigeria today, data on antimalarial drug utilization are scanty. Recent audits have focused on trends in the use of antimalarials prior and immediately after the introduction of the National Treatment Policy and studies were carried out in either secondary health care facilities or tertiary hospitals. ${ }^{6-8}$ It is necessary to survey antimalarial drug use years after introduction of antimalarial treatment guideline using secondary and tertiary hospitals to give a picture of the country's scenario. This study aimed to compare the patterns of antimalarial drug use with the current National Antimalarial Treatment Policy and to assess prescribing behaviour at the tertiary and secondary hospitals in Nigerian capital territory, Abuja.

\section{METHODS}

The drug utilization study was cross-sectional and retrospective, conducted from January to June, 2008 in two health facilities in Abuja - a secondary and a tertiary hospital. The two hospitals were chosen purposively so that results obtained could be generalized to other public hospitals. The hospitals were selected because of their closeness to seat of government in Nigeria and thus will be among the first public health centres to implement government policies. The tertiary hospital used was the National Hospital, Abuja located in the Central Area of the Federal Capital Territory (FCT). It has 200 beds though expansion projects are in progress. The outpatient department was used for the study. The secondary hospital - Wuse General Hospital is located in the heart of Abuja, Wuse. It is a 32-bed facility with six departments.

The population of study comprised of all outpatient prescriptions from January to June, 2008 in the two hospitals. Prescriptions that contained at least one antimalarial drug within the study period were retrieved. Prescriptions for pregnant women from ante-natal unit were excluded. The health professionals that took part in the survey were permanent staff of the hospitals who consented to the study. Only outpatient doctors were eligible for the study. An outpatient doctor was defined as a doctor that is specifically assigned to the outpatient department. All the hospital pharmacists were eligible for the study.

Two instruments were used. The first instrument was a modified World Health Organization (WHO) prescribing indicator form used to collect data from prescriptions. The other instrument was a facevalidated, semi-structured questionnaires used to collect information from the doctors and pharmacists on knowledge of Antimalarial Treatment Guideline (ATG).

Outpatient prescriptions from the two hospitals were collected and audited for the period of January to June, 2008. The collection and audit were done twice weekly by two pharmacists recruited to help in data collection. On each of the collection days, the whole prescriptions before that day were sorted and the ones containing antimalarials were separated from the pile. After sorting, a modified WHO prescribing indicator form was used to extract the following data: age; sex; number of drugs dispensed; number of drugs prescribed; and the names, formulations and dosages of the drugs prescribed. The WHO definition was used to identify an antibiotic. ${ }^{9}$ Other drug use indicators assessed were the number of drugs prescribed from the international non-proprietary name (INN) or generic name and the number of drugs prescribed from WHO model list or Nigerian Essential Drug List (EDL). ${ }^{9}$ The questionnaires were self-completed by health professionals in the two hospitals.

Statistical Package for Social Sciences (SPSS, version 11, Chicago, USA) and Microsoft Excel (Microsoft Corporation, 2007) were used for data analysis. Raw data were double checked with soft data for consistency. Drug use metric employed was number of prescription and drug use pattern was expressed in terms of DU90\%. The DU90\% segment reflects the number of drugs that account for $90 \%$ of drug prescriptions. Adherence with the regimens listed in the National Antimalarial Treatment Guideline (ATG) was assessed. Adherence was defined as number of prescribed regimens recommended from the national ATG divided by number of regimens in the DU90\% segment, expressed in percentage. Adjusted adherence represents the percentage of all 


\begin{tabular}{|c|c|c|c|}
\hline & $\begin{array}{l}\text { Wuse General HospitaL }{ }^{*}, N=3779 \\
\text { n (\%) }\end{array}$ & $\begin{array}{c}\text { National Hospital, } \mathrm{N}=2586 \\
\mathrm{n}(\%)\end{array}$ & $\begin{array}{c}\text { Total, } \mathrm{N}=6365 \\
\mathrm{n}(\%)\end{array}$ \\
\hline \multicolumn{4}{|l|}{ Gender } \\
\hline Female & $644(17.0)$ & $1526(59.0)$ & $2170(34.1)$ \\
\hline Male & $442(11.7)$ & $1035(40.0)$ & 1477 (23.2) \\
\hline Not Available & $2693(71.3)$ & $25(1.0)$ & $2718(42.7)$ \\
\hline \multicolumn{4}{|l|}{ Age } \\
\hline $0-3$ months & $35(0.9)$ & $24(0.9)$ & $59(1.0)$ \\
\hline 3months - 5years & $1793(47.4)$ & $907(35.1)$ & $2700(42.4)$ \\
\hline$>$ 5years & $1764(46.8)$ & $1623(62.8)$ & 3387 (53.2) \\
\hline Not Available & $187(4.9)$ & $32(1.2)$ & $219(3.4)$ \\
\hline
\end{tabular}

regimens listed in the national ATG in addition to 'other ACTs' not listed in national ATG. Chi-square test was used to test for association in use of antimalarial drugs among the two hospitals. A two tailed significance level of 0.05 was used.

Ethical approval for the study was obtained from National Hospital, Abuja. An informed consent letter was signed by the health professionals before administering the questionnaires. Confidentiality of the information supplied by the participants was guaranteed and the signed consent letters were stored separately from the completed questionnaires which does not bear the name of the participant.

\section{RESULTS}

\section{Sample size}

A total of 6365 prescriptions containing antimalarial drugs were audited, from both hospitals. This was $17.7 \%$ of the total prescriptions $(36,128)$ recorded for outpatient pharmacies for both hospitals during the 6-month study period. Retrieved prescriptions comprised of 2586 prescriptions $(40.6 \%)$ from tertiary hospital and 3779 prescriptions (59.4\%) from secondary hospital. Twenty-two questionnaires were given to outpatient doctors, but 17 were returned. A total of 30 questionnaires were given out to pharmacists in both hospitals and a total 27 was returned. Out of the 3 unreturned questionnaires, 2 were not filled by pharmacists in the tertiary hospital while 1 was not returned from the secondary hospital.

\section{Demographic data}

Some of the prescriptions had no data on sex and age of patients and so there was an additional group attached to the sex and age groupings, called 'Not Available' as shown in Table 1. There were a higher percentage of females from both hospitals. The prescriptions were more for patient above 5 years of age. Only a small percentage of the prescriptions were for patients between 0-3 months of age. However, the percentage of prescriptions were higher for patients less than 5years (48.3\%) in the secondary hospital.

In both hospitals, $52.9 \%$ were male doctors and $47.1 \%$ were female doctors. Most of the doctors were between the ages of $31-40$ years $(41.2 \%)$ and have practiced for a period of $1-10$ years $(47.1 \%)$. The proportion of female pharmacists $(59.3 \%)$ was higher than that of male pharmacists
(40.7\%). Most of the pharmacists were in the age groups of $30-40$ years $(40.7 \%)$ and $40-50$ years $(44.4 \%)$. Most of the pharmacists have either practiced for $1-10$ years $(48.1 \%)$ or $11-20$ years $(37.0 \%)$. Other patient and health professional demographic details are shown in Table 2.

\section{Drug use indicators}

Table 3 shows some of the drug use indicators measured against a WHO standard9. Tertiary hospital prescribed more injections compared to secondary hospital $(p<0.001)$. Also, tertiary hospital had a higher percentage of prescriptions with antibiotic(s) than secondary hospital $(p<0.001)$. The average number of drugs per encounter for the two hospitals was 2.5. Specifically, tertiary hospital had a higher number of drugs prescribed per encounter than secondary hospital $(p<0.001)$. Nevertheless, in terms of use of generic name and prescribing form essential drug list, tertiary hospital significantly scored better than secondary hospital $(p<0.001)$.

\section{Drug use and adherence to antimalarial treatment guideline}

Artemisinin based Combination Therapies (ACTs) were the most prescribed antimalarials $(81.4 \%)$ in both hospitals, followed by monotherapies (15.3\%) and lastly, the non-ACTs (3.2\%). Artemetherlumefantrine $(\mathrm{AL})(56.8 \%)$ was the most prescribed ACT, followed by artesunate/amodiaquine (9.3\%) and artesunate/sulfadoxine-pyrimethamine (9.3\%). Sulfadoxine-pyrimethamine (SP) $(4.9 \%)$ was the most prescribed monotherapy followed by Artesunate (3.2\%) and amodiaquine (3.2\%). Chloroquine prescriptions contributed $0.6 \%$ of all antimalarials prescribed in the two hospitals. NonACTs constituted a small percentage of overall antimalarial use in both hospitals, with amodiaquine/SP combination (3.0\%) being the most commonly used combination in this group.

Figure 1 shows the antimalarial drugs within the drug utilization (DU90\%) segment) in the two hospitals. Secondary hospital had only three drugs in the DU $90 \%$ segment and also had the highest ATG adherence of $66.7 \%$. However, tertiary hospital had a total of 13 drugs in the DU90\% segment and a low ATG adherence of $38.5 \%$. However, adjusted adherence was $69.2 \%$ in tertiary hospital. Adjusted adherence to ATG was not calculated for secondary hospital since they do not prescribe any other ACT apart from those listed in the national guideline. Overall analysis of data from the two hospitals showed a very low ATG adherence of only $25 \%$, made up of a total of eight drugs within DU90\% segment. Overall adjusted adherence was $50 \%$. 


\begin{tabular}{|c|c|c|c|}
\hline \multicolumn{4}{|l|}{ Doctors } \\
\hline Gender & Wuse General Hospital, $n=5$ & National Hospital, $\mathrm{n}=12$ & Total, $\mathrm{n}=17$ \\
\hline Female & $1(20.0)$ & $7(58.3)$ & $8(47.1)$ \\
\hline Male & $4(80.0)$ & $5(41.7)$ & 9 (52.9) \\
\hline \multicolumn{4}{|l|}{ Age } \\
\hline $20-30$ years & $1(20.0)$ & $4(33.3)$ & $5(31.3)$ \\
\hline $31-40$ years & $4(80.0)$ & $3(25.0)$ & $7(41.2)$ \\
\hline $41-50$ years & - & $4(33.3)$ & $4(23.5)$ \\
\hline $51-60$ years & - & $1(8.3)$ & $1(6.0)$ \\
\hline 60 and above & - & - & \\
\hline \multicolumn{4}{|l|}{ Number of years of practice } \\
\hline $1-10$ years & $3(60.0)$ & $5(41.7)$ & $8(47.0)$ \\
\hline $11-20$ years & $2(40.0)$ & $5(41.7)$ & $7(41.2)$ \\
\hline $21-30$ years & - & $1(8.3)$ & $1(5.9)$ \\
\hline $31-40$ years & - & - & - \\
\hline Above 40 years & - & $1(8.3)$ & $1(5.9)$ \\
\hline \multicolumn{4}{|l|}{ Pharmacists } \\
\hline Gender & Wuse General Hospital, $\mathrm{n}=8$ & National Hospital, $\mathrm{n}=19$ & Total, $\mathrm{n}=27$ \\
\hline Female & $5(62.5)$ & $11(57.9)$ & $16(59.3)$ \\
\hline Male & $3(37.5)$ & $8(42.1)$ & $11(40.7)$ \\
\hline \multicolumn{4}{|l|}{ Age } \\
\hline $20-30$ years & - & $4(21.0)$ & $4(14.8)$ \\
\hline $31-40$ years & $2(25.0)$ & $9(47.4)$ & $11(40.7)$ \\
\hline $41-50$ years & $6(75.0)$ & $6(31.6)$ & $12(44.4)$ \\
\hline $51-60$ years & - & - & - \\
\hline 60 and above & - & - & - \\
\hline \multicolumn{4}{|l|}{ Number of years of practice } \\
\hline $1-10$ years & $2(25.0)$ & $11(57.9)$ & $13(48.1)$ \\
\hline $11-20$ years & $4(50.0)$ & $6(31.6)$ & $10(37.0)$ \\
\hline $21-30$ years & $2(25.0)$ & $2(10.5)$ & $4(14.8)$ \\
\hline $31-40$ years & - & - & - \\
\hline Above 40 years & - & - & - \\
\hline
\end{tabular}

\begin{tabular}{|l|c|c|c|c|}
\hline Table 3: Drug Use Indicators & $\begin{array}{c}\text { Wuse General Hospital, } \\
\mathrm{N}=3779\end{array}$ & $\begin{array}{c}\text { National Hospital, } \\
\mathrm{N}=2856\end{array}$ & $\begin{array}{c}\text { Total, } \\
\mathrm{N}=6365\end{array}$ & $\mathrm{P}$-value \\
\hline Average number of drugs per encounter & 1.73 & 3.62 & 2.50 & $\mathrm{p}<0.001$ \\
\hline$\%$ of drugs prescribed by generics & $27.68 \%$ & 47.86 & $39.56 \%$ & $\mathrm{p}<0.001$ \\
\hline$\%$ of encounters with an antibiotics & $10.90 \%$ & $40.40 \%$ & $22.9 \%$ & $\mathrm{p}<0.001$ \\
\hline$\%$ of encounters with an injection & $0.46 \%$ & $13.77 \%$ & $5.8 \%$ & $\mathrm{p}<0.001$ \\
\hline$\%$ of drugs from WHO* model list or $\mathrm{EDL}^{\#}$ & $85.76 \%$ & $78.32 \%$ & $81.36 \%$ & $\mathrm{p}<0.001$ \\
\hline$\%$ of drugs actually dispensed & $99.27 \%$ & $71.39 \%$ & $82.82 \%$ & $\mathrm{p}<0.001$ \\
\hline $\begin{array}{l}\text { *World Health Organization } \\
\text { \#Essential Drug List }\end{array}$ & & & \\
\hline
\end{tabular}

\section{Knowledge of antimalarial treatment guideline by health personnel}

The percentage of health care providers that were aware of the national Antimalarial Treatment Guideline was $88.2 \%$ and $85.1 \%$ for doctors and pharmacists respectively. However, while all (100\%) the doctors in $\mathrm{NH}$ were aware of the ATG, only $60 \%$ of doctors in WGH were aware of the ATG. Also, $13.3 \%$ of the doctors and $52.2 \%$ of the pharmacists could not properly list drugs specified in the guideline for management of uncomplicated and complicated malaria. Amodiaquine was the most commonly preferred option for managing children aged 0-3 months with malaria infection against the indicated oral quinine.

\section{DISCUSSION}

This study revealed significant use of artemisinin based combination therapy for the treatment of uncomplicated malaria. However, prescribers did not adhere strictly to the drugs indicated in national ATG. The study also highlighted poor use of generic name in prescriptions and unawareness of the drugs indicated in the Nigerian antimalarial treatment guideline by health professionals especially pharmacists.

Use of ACTs was high in the hospitals studied, especially the drug of choice, artemetherlumefantrine, for treatment of uncomplicated malaria infections. This is quite different from what has been reported in other studies in Nigeria ${ }^{6,10}$ and in other African countries. ${ }^{11-13}$ This was not the case before now as studies conducted prior to switch from monotherapy to ACTs recorded predominant prescriptions of monotherapy especially with chloroquine and SP. For instance, a survey conducted in a period when Nigeria was transiting from chloroquine to ACTs as recommended treatment for uncomplicated malaria showed $77 \%$ 


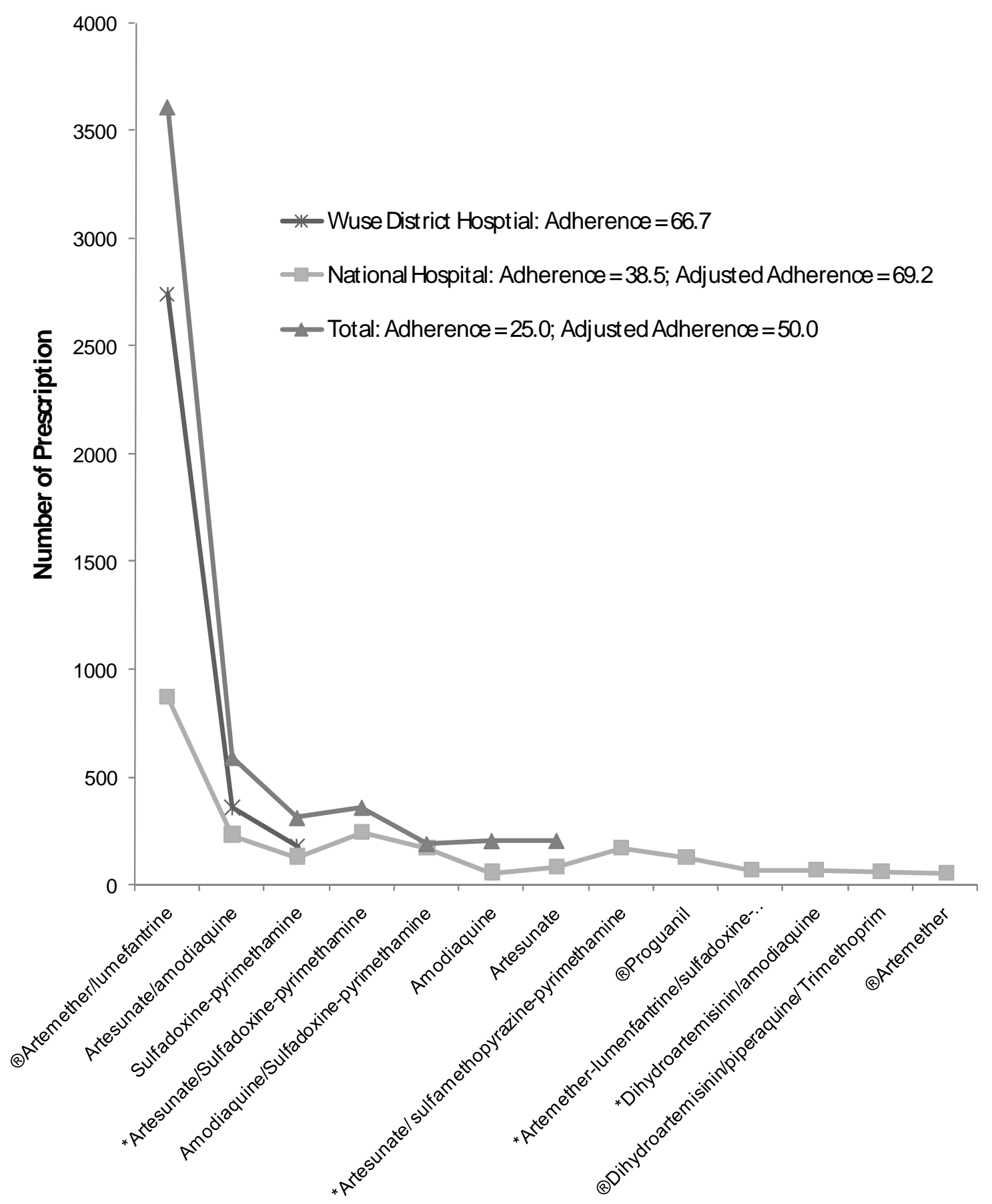

Figure 1: Drug utilization ninety percent (DU90\%) of antimalarials in two Nigerian hospitals ®Antimalarial regimens that are listed in the National Antimalarial Treatment Guideline (ATG)

*Antimalarial regimens that are not listed in the National ATG, but can be referred to as "recommended" treatment as they contain an artemisinin derivative and partner drug(s)

Adherence - based on the regimens listed in the national ATG

Adjusted Adherence - based on both the regimens listed in the National ATG or regarded as a recommended option

monotherapy prescriptions with chloroquine, SP and artemisinin derivatives alone being the commonest prescriptions. ${ }^{10}$ The change in pattern of antimalarial drug utilization observed in this study can only be attributed to the change in sensitivity to antimalarials from monotherapies to ACTs. The study also observed that the total number of patients above five years was higher. This is attributed to the fact that most of the patients in $\mathrm{NH}$ were above five years unlike in Wuse hospital were majority of the patients were less than five years. The tertiary hospital being the last point of referral will usually have these children, particularly the under five years, presenting there with severe malaria necessitating admission. Thus, as only outpatient prescriptions were used, it would definitely not capture the true population of patients 
less than five years with malaria in the tertiary hospital.

Number of drugs in the DU90\% segment for antimalarial drugs was four times higher in the tertiary hospital compared to the secondary hospital. It has been suggested that the use of large number of drug alternatives in a therapeutic choice set could result in a less rational clinical decision making process. ${ }^{14}$ Generally, there is need to improve clinical decision making in order to reduce practice variation, preventable errors and to support the delivery of evidence-based medicines. ${ }^{15}$ The use of smaller set of antimalarial drug could help achieve this. In this study, non recommended monotherapies were noted to be used for treatment of malaria. The presence of many non recommended monotherapies - SP, AQ and artesunate - in the DU90\% segment poses serious concern especially considering the fact that SP and amodiaquine have been reported to be less effective for uncomplicated malaria treatment in Nigeria due to $P$. falciparum resistance to them. ${ }^{16}$ Another observation was the use of artesunate as monotherapy. The use of artemisinin and its derivatives as single agents is not recommended since infections often relapses. ${ }^{17}$

Average number of drugs prescribed per encounter in the tertiary hospital was higher than that of secondary hospital. The result obtained from this study is comparable with the value gotten from a previous WHO study in Nigeria ${ }^{9}$ as well as in two tertiary hospitals in North Western Nigeria. ${ }^{18} \mathrm{~A}$ plausible reason for this greater polypharmacy in tertiary hospital might be due to the complex nature of cases handled in this referral centre by doctors of different specialties. The study also revealed a high rate of prescribing by brand names in both hospitals. The overall low generic prescribing observed was comparable to the value observed by another study conducted in Nigeria. ${ }^{19}$ National Drug Policy of Nigeria, published in 2005 stipulates that procurement and prescribing of drugs in the public sector shall be by International Non-proprietary Names (INN) or generic names only and through an open-competitive tender conducted in a transparent manner with advice of the pharmacy department. ${ }^{1}$ There is a clear need to ensure prescription of drugs by generic name, as purchasing and prescribing by generic name carry considerations of clarity, quality and price advantage. The use of injections was low, though comparably higher in tertiary hospital. However, the practice of using disposables as was observed in the two hospitals reduces the risk of spread of blood borne infections. $^{20}$ The high number of essential drugs prescribed per patient was commendable and offer many advantages, including good quality, reduced cost, safety and effectiveness. This could probably be due to the positive effect of drug revolving fund programme.

On the assessment of knowledge of ATG by health professionals, the percentage of doctors that generally were aware and could also list correctly the recommended drugs was high. On the other hand, even though awareness and true knowledge of ATG among the doctors were high, both ATG adherence and 'adjusted adherence' were not quite high. The reason could either be in an observed change in the pattern of response to the listed ATG options or that despite adequate knowledge/awareness, guidelines are not followed in practice. To buttress these points, is the fact that even though doctors in $\mathrm{NH}$ were more aware of the existence of an ATG compared to their counterparts in the secondary hospital, their adherence ratio was lower than that of the secondary hospital. However, the adjusted adherence ratio of $\mathrm{NH}$ was higher than that ATG adherence for WGH. This could be due to a possible observed change in pattern of response to listed drugs by $\mathrm{NH}$ doctors. For example, the use of $\mathrm{AL}$ with SP was predominant (among the DU90\% drugs) in $\mathrm{NH}$. The rationale behind this combination as was given by some doctors in $\mathrm{NH}$ was synergy and thus increased efficacy with the AL-SP combination as against $\mathrm{AL}$ or AS-SP combinations alone. This quoted 'increased efficacy' of AL-SP combinations over AL or AS-SP alone, needs to be investigated further. There were however, few doctors that were unaware of the existence of ATG and lack of knowledge of ATG by doctors has serious implications as these doctors will continue to prescribe these older ineffective therapies for their patients. Amodiaquine was the most preferred drugs indicated by all the doctors for treating malaria in children less than 3 months of age. All other listed drugs are contrary to the ATG recommended choice of oral quinine in this age group. The reason behind this deviation needs further investigation. On the same vein, even though most of the pharmacists were aware of the ATG, further assessment showed that awareness does not necessarily translate to true knowledge as many pharmacists could not list correctly the drugs recommended in the National ATG for treatment of uncomplicated malaria. The new role of pharmacist stipulates that they should responsibly provide drug therapy with the goal of achieving optimal therapeutic outcome. ${ }^{21}$ Notwithstanding the fact that pharmacists in Nigerian hospitals as yet do not prescribe medications, they can affect the prescription by drawing the attention of the prescribing doctor to any observed error or inappropriate prescriptions. However, this advisory role can only be possible if the pharmacists are not only aware of these guidelines, but also know the correct drugs specified in them. There is need for inservice training and continuing education for pharmacists to keep them abreast with evidence based practice.

Our study had some limitations. A primary limitation of the study was that the prescription data collection was retrospective and so used pharmacy outpatient prescription sales only. This made it impossible for such outcome data like parasitological or clinical improvement data and other patient clinical profiles to be collected. Thus, drug utilization could not be linked with the clinical judgements that informed the prescriptions nor could it be related to medical outcome. However, only prescription data have been used to describe quality indicator indexes of drug prescribing - DU90\% and this DU90\% has been described as an inexpensive, flexible and 
simple method of assessing the quality of drug prescribing in routine healthcare. ${ }^{22}$ Only secondary and tertiary hospitals were used which may affect the generalizability of the results. However, exclusion of primary health care center was due to the fact that most of these primary health care centers are not functional and even the functional ones do not keep proper medical records.

\section{CONCLUSIONS}

This study showed an increased use of artemisinin based combination therapy for the treatment of uncomplicated malaria compared to previous reports in Nigeria. However, there is need for health professionals to adhere to stipulated therapeutic options in national Antimalarial Treatment Guideline to ensure evidence based practice. There is also need to explore ways to ensure the standard practice of prescribing with generic name. This study also highlights the need for not only periodic in-service training for health professionals, but also the need for quality assurance through monitoring of adherence to clinical guidelines to ensure the practice of evidence based medicine.

\section{CONFLICT OF INTEREST}

The authors declare no conflict of interest.

\section{References}

1. Federal Ministry of Health: The National Health Policy of Nigeria. Federal Ministry of Health, Abuja Nigeria. 1992.

2. Band JR. Resurgent malaria at the millennium: control strategies in crisis. Drugs. 2000;59:719-743.

3. Guerin PJ, Olliaro P, Nosten F, Druilhe P, Laxminarayan R, Blinka F, Kilama WL, Ford N, White J. Malaria: current status of control, diagnosis, treatment and a proposed agenda for research and development. Lancet Infect Dis. 2002;2:564573.

4. Baird JK. Effectiveness of Antimalarial Drugs. N Engl J Med. 2005;352:1565-1577.

5. Biswas NR, Biswas RS, Pal PS, Jain SK, Malhotra SP, Gupta A, Pal SN. Patterns of prescriptions and drug use in two tertiary hospitals in Delhi. Ind J Physiol Pharmacol. 2000;44:109-112.

6. Ukwe CV, Ekwunife OI. Drug utilization study of antimalarials for the treatment of hospitalized children under five in south-eastern Nigeria. Pharmacoepdemiol Drug Saf. 2008;17:1183-1188.

7. Mokuolu OA, Okoro EO, Ayetoro SO, Adewara AA. Effect of artemisinin-based treatment policy on consumption pattern of antimalarials. Am J Trop Med Hyg. 2007;76(1):7-11.

8. Oshikoya KA. Antimalarial Prescriptions for Children Presenting with Uncomplicated Malaria to a Teaching Hospital in Nigeria after the Change of National Guidelines for Malaria Treatment. World J Med Sci. 2007;2(1):49-53.

9. How to investigate drug use in health facilities: selected drug indicators. Action Programme on Essential Drugs (WHO/DAP/ (93.11) Geneva, World Health Organization, 1993.

10. Meremikwu M, Okomo U, Nwachukwu C, Oyo-Ita A, Eke-Njoku J, okebe J, Oyo-lta E, Garner P. Antimalarial drug prescribing practice in private and public health facilities in south-east Nigeria: a descriptive study. Malar J. 2007;6:55.

11. Dodo ANO, Fogg C, Asiimwe, Nartey ET, Kodua A, Tenkorang O, Ofori-Adjei D. Pattern of drug utilization for treatment of uncomplicated malaria in urban Ghana following national treatment policy change to artemisinin-combination therapy. Malar J. 2009;8:2.

12. Munier A, Diallo A, Cot M, Ndiaye O, Arduin P, Chippaux J. Antimalarial prescriptions in three health care facilities after the emergence of chloroquine resistance in Niakhar, Senegal (1992-2004). Malar J. 2009;8:83.

13. Baume C, Helitzer-Allen D, Achur P. Patterns of care for childhood malaria in Zambia. Soc Sci Med. 2005;51:14911503.

14. Popa C. DU90 for the assessment of drug prescribing in a primary care. MPH 2005:18.

15. Bornstein BH, Emier AC. Rationality in medical decision-making: a review of the literature on doctors' decision- making biases. J Eval Clin Pract. 2001;7:97-107.

16. Federal Ministry of Health. National Antimalarial Treatment Policy. Federal Ministry of Health, Nigeria. 2005.

17. Tracy JW, Webster LT. Malaria In: Hardman JG, Limbird LE, Gilman AG (Ed). Goodman and Gilman's - The pharmacological basis of therapeutics. 10 edition. McGraw-Hill Companies, Inc. Unites States of America. 2001. Pp1075(1069-1095).

18. Ibrahim MTO. Physicians' prescribing behaviour in two tertiary health care facilities in north western Nigeria. Analysis of 518 prescriptions. Sahel Med J. 2004;7:115-118.

19. Akande TM, Ologe MO. Prescription pattern at a secondary health care facility in llorin, Nigeria. Ann Afr Med. 2007;6(4):186-189.

20. Lamichane DC, Giri BR, Pathak OK, Panta OB, Shankar PR. Morbidity profile and prescribing pattern among outpatient in a tertiary teaching hospital in western Nepal. McGill J Med. 2006;9(2):126-133.

21. Helper CD, Strand LM. Opportunities and Responsiblities in Pharmaceutical Care. Am J Hosp Pharm. 1990;43:533-534.

22. Bergman U, Popa C, Tomson Y, Wettermark B, Einarson TR, Åberg H, Sj qvist F. drug utilization $90 \%$ - a Simple Method for assessing the quality of drug prescribing. Eur J Clin Pharmacol. 1998;54:113-118. 